Archive for

Organic Chemistry

Arkivoc 2020, part vi, 228-237

\title{
Flash vacuum pyrolysis of 2-acetyl-3-azido[1]benzothiophene
}

\author{
Alexander P. Gaywood, ${ }^{a}$ Hamish McNab, ${ }^{\# a}$ and Lilian McNab*b \\ ${ }^{a}$ School of Chemistry, The University of Edinburgh, West Mains Road, Edinburgh EH9 3JJ, UK \\ ${ }^{b} 6$ Torphin Road, Edinburgh EH13 OHW \\ ${ }^{\#}$ Deceased $15^{\text {th }}$ November 2010 \\ E-mail:Lilian.McNab@gmail.com
}

Received 05-07-2020

Accepted 07-20-2020

Published on line $\quad 07-25-2020$

\section{Abstract}

Flash vacuum pyrolysis (FVP) of 2-acetyl-3-azido[1]benzothiophene at $300{ }^{\circ} \mathrm{C}$ provides 3-methyl [1]benzothieno[3,2-c]isoxazole (72\%). At higher temperatures, the heteroindoxyl 1,2-dihydro[1]benzothieno[3,2-b]pyrrol-3-one was obtained in low yield (ca. 10\%). The heteroindoxyl exists as a mixture of keto and enol forms in DMSO solution. Because of the easy oxidative dimerisation of these products to indigotin (and its heteroanalogues), such reactions are excellent examples of the synthetic advantages of FVP with the monomeric products conveniently generated under vacuum in a solvent-free, air-free environment.

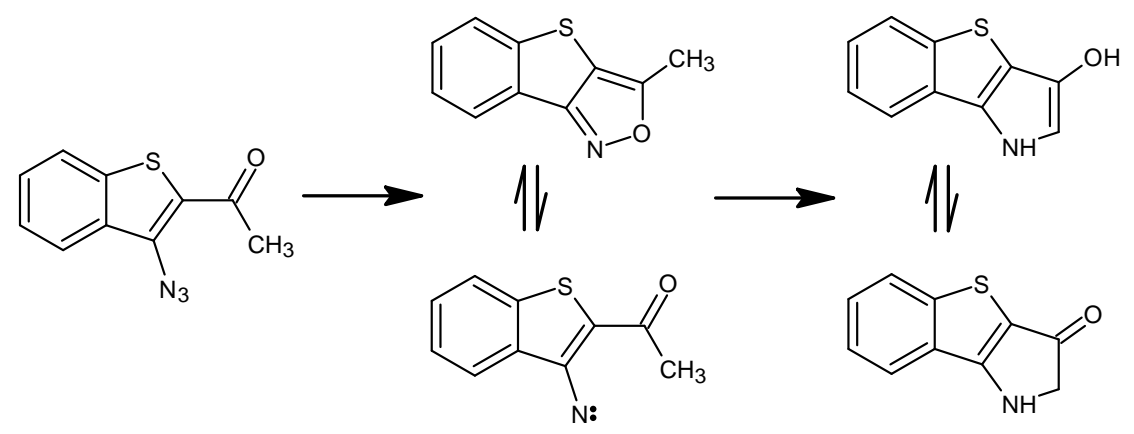

Keywords: Flash vacuum pyrolysis, FVP, heteroindoxyl, nitrene, fused heterocycles 


\section{Introduction}

We have recently employed a gas-phase nitrene insertion process to generate indoxyl (1) $)^{1}$ and its heterocyclic analogues $(\mathbf{3})^{2}$ and $(\mathbf{4})^{3}$ under flash vacuum pyrolysis (FVP) conditions (Scheme 1). Azides or fused tetrazoles were used as precursors to the nitrene (e.g., 2). ${ }^{1-3}$ Because of the easy oxidative dimerisation of these products to indigotin (5) (and its heterocyclic analogues) such reactions are excellent examples of the synthetic advantages of FVP with the monomeric products conveniently generated under vacuum in a solventfree, air-free environment.
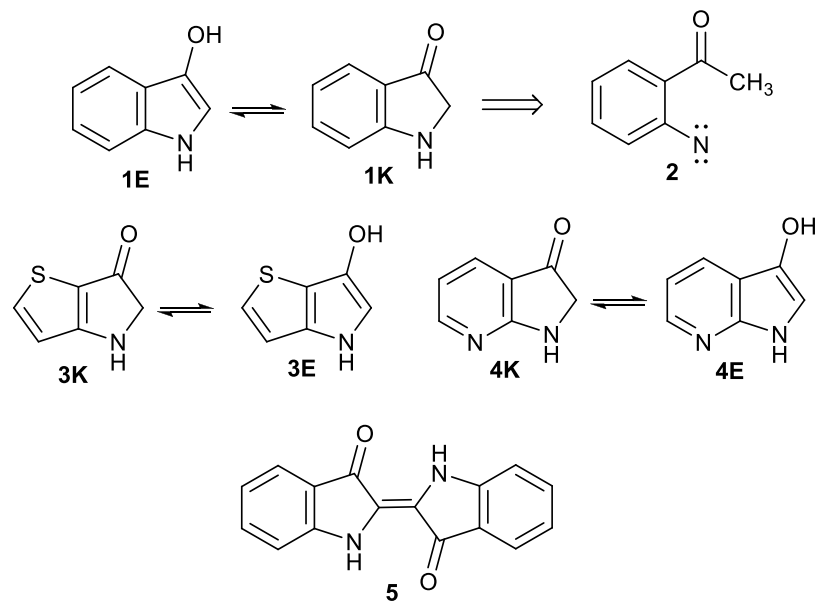

\section{Scheme 1}

Unfortunately, application of the method to the quinoline analogue (6) gave the dinitrile (7) as the major product. We believe this product is formed via a known nitrene insertion in the hetero ring $^{4}$, and subsequent rearrangements in which the elimination of ketene is the final step. Although the heteroindoxyl (8) could be reliably detected in the complex pyrolysate, it was never the major product and proved too unstable to isolate (Scheme 2). ${ }^{3}$ In this paper, we complete our current studies of heteroindoxyls by using the nitrene strategy to achieve the successful synthesis of the benzothiophene analogue of 3, viz. 1,2-dihydro[1]benzothieno[3,2b]pyrrol-3-one (9). This example demonstrates that the presence of a fused benzene ring in the precursor does not necessarily preclude the formation of an indoxyl by the nitrene strategy. In addition, a detailed comparison is now possible between the behaviour of the azide precursors to $\mathbf{1}, \mathbf{3}$ and $\mathbf{9}$ and the tautomeric properties of the products.<smiles></smiles>

Scheme 2. Reagents and conditions: (i) FVP $600{ }^{\circ} \mathrm{C}$. 


\section{Results and Discussion}

A one-step route to 2-acetyl-3-amino[1]benzothiophene (10) is available ${ }^{5}$; this product was obtained in $80 \%$ yield after a $16 \mathrm{~h}$ reaction time (see Supplementary Material file, p. S2). Since the structure of the corresponding 2-acetyl-3-amino[1]benzofuran has been reported, ${ }^{6}$ the X-ray crystal structure of 10 was obtained for comparison (Fig. 1); there are two molecules in the asymmetric unit (data for the second molecule and the benzofuran equivalent are shown in Table 1). The heavy atom skeleton of the molecule, as a whole, is planar mean deviation from best plane $0.095 \AA$ ( $0.034 \AA$ ). Maximum deviation from best plane is $0.0245 \AA$ at $\mathrm{C}(11)$ [0.0895 $\AA$ at $\mathrm{C}(21)$ ]. There is intramolecular hydrogen bonding between the $\mathrm{NH}$ and the $\mathrm{C}=\mathrm{O}$ of the acetyl group $\{\mathrm{H}(31)-\mathrm{O}(10) 2.14 \AA[\mathrm{H}(131)-\mathrm{O}(20) 2.16 \AA]\} ; \mathrm{N}(3)-\mathrm{O}(10) 2.758(2) \AA[\mathrm{N}(13)-\mathrm{O}(20) 2.7831(19)$ $\AA$ ]; angle at hydrogen $\left.126^{\circ}\left(125^{\circ}\right)\right\}$ which means that $C(2)-C(10)$ adopts an $s-E$ configuration. With the exception of the region around the heteroatom, there are no significant differences in bond lengths between the benzothiophene (10) and the corresponding benzofuran. ${ }^{6}$ Similarly, the expected push-pull conjugation between $\mathrm{N}(3)$ and the carbonyl group of $\mathbf{1 0}$ has little effect on the $\mathrm{C}(2)-\mathrm{C}(3)$ bond length, by comparison with a 2-aroylbenzothiophene previously reported. ${ }^{7}$

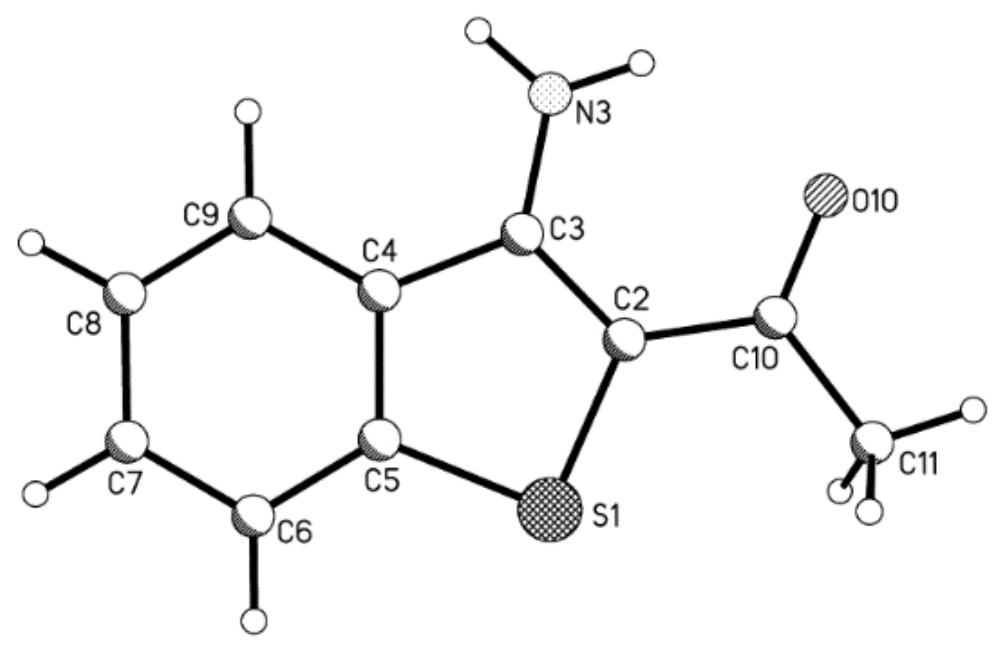

Figure 1. Plot of one of the molecules of $\mathbf{1 0}$ showing the crystallographic numbering scheme. 
Table 1. Bond lengths of benzothiophene molecules of $\mathbf{1 0}$ found in asymmetric units of crystal structure (crystallographic numbering)

\begin{tabular}{cccc}
\hline Bond & $\begin{array}{c}\text { Benzothiophene } \\
\text { (Asymmetric Unit 1) }\end{array}$ & $\begin{array}{c}\text { Benzothiophene } \\
\text { (Asymmetric Unit 2) }\end{array}$ & $\begin{array}{c}\text { Benzofuran } \\
\text { Equivalent }\end{array}$ \\
\hline S1-C5 & $1.7353(15)$ & $1.7300(16)$ & $1.360(3)$ \\
S1-C2 & $1.7548(14)$ & $1.7581(15)$ & $1.404(3)$ \\
C2-C10 & $1.434(2)$ & $1.430(2)$ & $1.420(4)$ \\
C2-C3 (b) & $1.387(2)$ & $1.390(2)$ & $1.378(3)$ \\
C3-C4( & $1.445(2)$ & $1.447(2)$ & $1.447(4)$ \\
C3-N3 & $1.351(2)$ & $1.346(2)$ & $1.355(3)$ \\
C4-C9 & $1.399(2)$ & $1.399(2)$ & $1.394(4)$ \\
C4-C5 & $1.407(2)$ & $1.406(2)$ & $1.399(3)$ \\
C5-C6 & $1.398(2)$ & $1.398(2)$ & $1.381(4)$ \\
C6-C7 & $1.382(3)$ & $1.380(3)$ & $1.380(4)$ \\
C7-C8 & $1.398(3)$ & $1.397(3)$ & $1.399(4)$ \\
C8-C9 & $1.383(2)$ & $1.384(2)$ & $1.381(4)$ \\
C10-C11 & $1.504(2)$ & $1.505(3)$ & $1.489(4)$ \\
C10-O10 & $1.242(2)$ & $1.247(2)$ & $1.245(3)$ \\
\hline
\end{tabular}

Due to the low solubility of $\mathbf{1 0}$ in dilute $\mathrm{HCl}$, standard diazotization conditions gave only recovered starting material. When phosphoric acid was used instead, however, the increased solubility of 10 (and its phosphate salt) in the medium allowed diazotization and reaction with sodium azide to provide the azidobenzothiophene (11) in $47 \%$ yield, initially as a foam which could be purified by recrystallisation (Scheme 3 ).

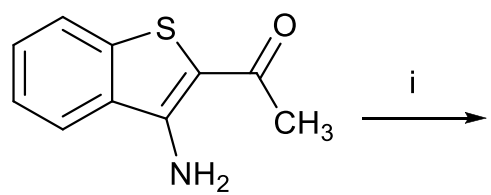

10<smiles>CC(=O)c1sc2ccccc2c1N</smiles>

11

Scheme 3. Reagents and conditions: (i) $\mathrm{NaN}_{3}, \mathrm{H}_{3} \mathrm{PO}_{4}, 0-20{ }^{\circ} \mathrm{C}, 47 \%$.

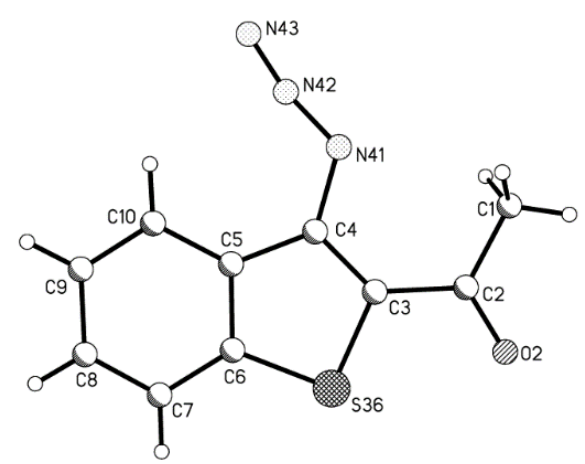

Figure 2. Plot of one of the molecules of $\mathbf{1 1}$ showing crystallographic numbering scheme. 
The X-ray crystal structure of the azide (11) again shows two molecules in the asymmetric unit. In common with other covalently-bonded azides, ${ }^{8}$ the azide function itself is non-linear (data for the second molecule are given in parentheses) $\left\{\mathrm{N}(41)-\mathrm{N}(42)-\mathrm{N}(43) 169.40(12)^{\circ}\left[169.21(12)^{\circ}\right]\right\}$ and points in the opposite direction to the carbonyl of the acetyl group. In addition, the two $N-N$ bonds have very different bond lengths $\{\mathrm{N}(41)-\mathrm{N}-42)$ $1.2425(13) \AA[1.2397(14) \AA]$ : N(42)-N(43) 1.1284(14) $\AA$ [1.1293(15) $\AA$ ] $\}$, another general feature of covalent azide geometry. ${ }^{8}$ In the absence of hydrogen bonding, the acetyl group itself adopts the opposite (s-Z) configuration to that of the acetyl group of the amine (10) (s-E).

FVP of the azide (11) was complete at $300{ }^{\circ} \mathrm{C}$, producing 3-methyl[1]benzothieno[3,2-c]isoxazole (12) (72\%). The parent benzothienoisoxazole is the only previously known example of this ring system and it was prepared from 3-azido[1]benzothiophene-2-carboxaldehyde by a solution-phase nitrene insertion strategy. ${ }^{9}$ FVP of 11 at higher temperatures $\left(>500{ }^{\circ} \mathrm{C}\right)$ resulted in rearrangement to the poorly soluble heteroindoxyl (9) via the nitrene (13), accompanied by a range of more soluble byproducts which contributed to the low isolated yield of 9 (11\%). FVP of the isoxazole (12) at $600^{\circ} \mathrm{C}$ gave a similar, complex, pyrolysate. The product (9) was characterised by the $\mathrm{CH}_{2}$ resonance of the keto form $9 \mathrm{~K}\left[\delta_{\mathrm{H}}(9 \mathrm{~K}) 4.32-c\right.$.f. $\left.\delta_{\mathrm{H}}(3 \mathrm{~K})^{2} 4.22\right]$ and the $\mathrm{CH}$ resonance of the enol form $\left[\delta_{\mathrm{H}}(9 \mathrm{E}) 6.62-c . f . \delta_{\mathrm{H}}(3 \mathrm{E})^{2} 6.51\right]$; both tautomeric forms of 9 were present in DMSO solution (see below).

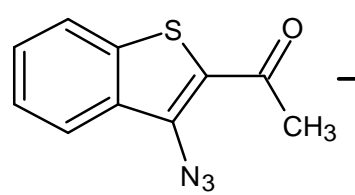

11

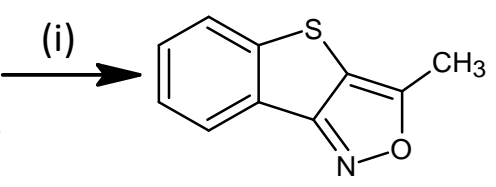

12

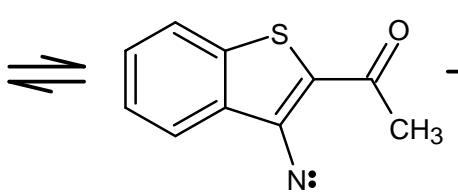

13

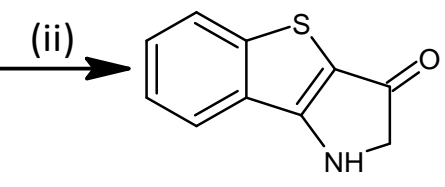

9

Scheme 4. FVP of azidobenzothiophene (11) at (i) $300{ }^{\circ} \mathrm{C}$ and (ii) $500{ }^{\circ} \mathrm{C}$.

The temperature profile for the decomposition of the azide (11) is shown in Fig. 3, and key parameters are listed in Table 2 with those for the sequences $14 \rightarrow \mathbf{1 5} \rightarrow \mathbf{1}$ and $\mathbf{1 6} \rightarrow \mathbf{1 7} \rightarrow \mathbf{3}$ listed for comparison (Scheme 5 ). Data for the benzothiophene sequence $(\mathbf{1 1} \rightarrow \mathbf{1 2} \rightarrow \mathbf{9})$ are rather similar (within $25^{\circ} \mathrm{C}$ ) to those for the transformation of 2-acetylphenyl azide (14) to indoxyl (1) via anthranil $(15)^{1}$, but both differ from the corresponding parameters for the thiophene $(\mathbf{1 6} \rightarrow \mathbf{1 7} \rightarrow \mathbf{3})$. In particular, the azide $(\mathbf{1 6})$ requires a higher temperature than $\mathbf{1 1}$ or $\mathbf{1 4}$ for complete decomposition, and the onset of formation of the thienopyrrolone (3) occurs at a much lower temperature $\left(\geq 125^{\circ} \mathrm{C}\right)$ than for $\mathbf{1}$ or $\mathbf{9}$, so there is no temperature at which the thieno[3,2-c]isoxazole $\mathbf{1 7}$ is the sole product.
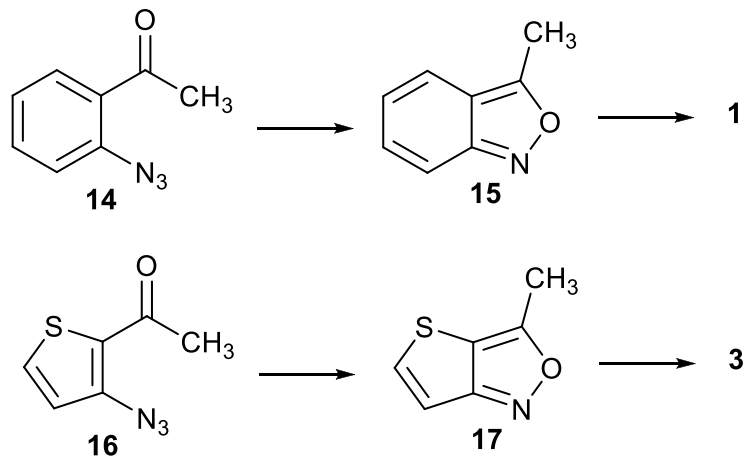

Scheme 5. Comparison of ring systems. 
The thermal reactivity of the azide (11), and stability of the isoxazole (12), relative to their monocyclic analogues (16) and (17), may be qualitatively rationalised by the maintenance of aromaticity in the benzene ring of 12, whereas the aromaticity of the thiophene ring is lost in the formation of 17 . Despite the apparent 0 quinonoid character of anthranil (15), it is known that such structures maintain significant aromatic character $^{10}$ which may account for the similarity in behaviour of $\mathbf{1 4} \rightarrow \mathbf{1 5} \rightarrow \mathbf{1}$ and $\mathbf{1 1} \rightarrow \mathbf{1 2} \rightarrow \mathbf{9}$.

Table 2. Key parameters from the temperature profiles of the FVP reactions of $\mathbf{1 1}, \mathbf{1 4}$ and $\mathbf{1 6}$

\begin{tabular}{|c|c|c|c|c|}
\hline & $\begin{array}{c}>95 \% \\
\text { azide } \\
\text { decomp }\end{array}$ & $\begin{array}{c}>5 \% \\
\text { isoxazole }\end{array}$ & $\begin{array}{c}>5 \% \\
\text { indoxyl }\end{array}$ & $\begin{array}{l}>95 \% \\
\text { indoxyl }\end{array}$ \\
\hline $\begin{array}{l}\text { Indoxyl series }^{1} \\
\quad(\mathbf{1 4} \rightarrow \mathbf{1 5} \rightarrow \mathbf{1})\end{array}$ & $300^{\circ} \mathrm{C}$ & $200{ }^{\circ} \mathrm{C}$ & $400^{\circ} \mathrm{C}$ & $575^{\circ} \mathrm{C}$ \\
\hline $\begin{array}{l}\text { Thiophene } \\
\text { Series }^{2} \\
(\mathbf{1 6} \rightarrow \mathbf{1 7} \rightarrow \mathbf{3})\end{array}$ & $325^{\circ} \mathrm{C}$ & $225^{\circ} \mathrm{C}$ & $250^{\circ} \mathrm{C}$ & $525^{\circ} \mathrm{C}$ \\
\hline $\begin{array}{l}\text { Benzothiophene } \\
\text { series } \\
\qquad(\mathbf{1 1} \rightarrow \mathbf{1 2} \rightarrow \mathbf{9})\end{array}$ & $275^{\circ} \mathrm{C}$ & $<200^{\circ} \mathrm{C}$ & $375^{\circ} \mathrm{C}$ & $525^{\circ} \mathrm{C}$ \\
\hline
\end{tabular}

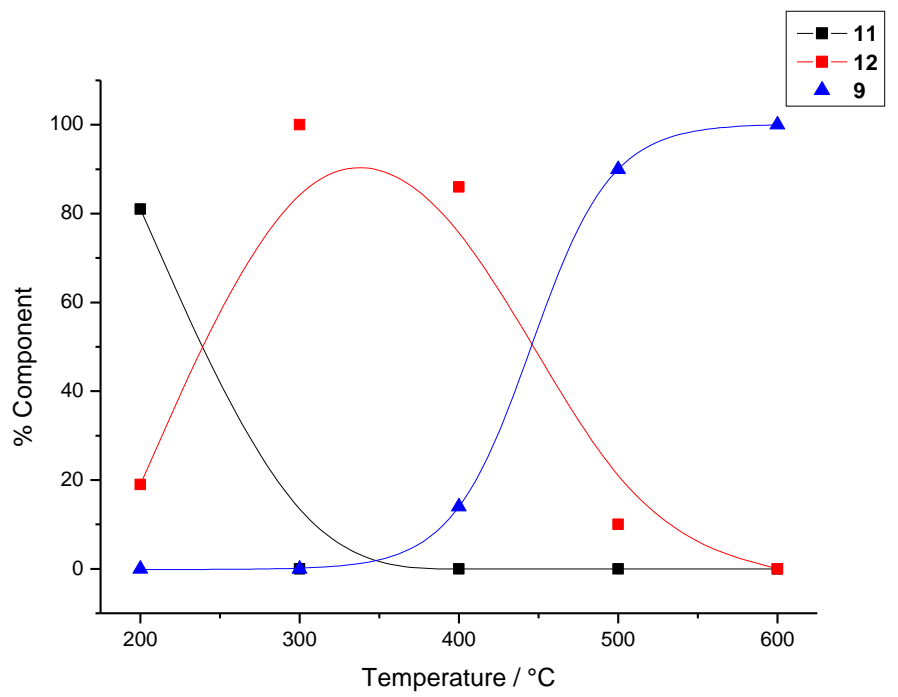

Figure 3. Temperature-conversion graph for FVP of 11, showing the relative amounts of 11, 12 and 9.

Because of the low yield of 9 and its poor solubility, it was not possible to study its chemistry in detail. A complete NMR characterisation of both keto (9K) and enol (9E) forms, however, was carried out in DMSO solution. When first dissolved, the solution contained essentially $100 \%$ keto tautomer, suggesting that 9 exists in the keto form (9K) in the solid-state. After several hours in solution, the enol form (9E) predominated (ca. 80\%). By comparison, indoxyl itself is present as the enol form (1E) almost exclusively (>95\%) in DMSO, whereas the thiophene analogue (3) shows an unexpected preference for the keto form (3K) (80\%) in the same solvent. ${ }^{2}$ 


\section{Conclusions}

This work has established that the nitrene strategy to heteroindoxyls under FVP conditions is compatible with the presence of a fused benzene ring in the precursor. Unlike its non-benzannulated anlogue, the kinetic product of the pyrolysis, 3-methyl[1] benzothieno[3,2-c]isoxazole (12), is stable over a range of temperatures. Rearrangement to the heteroindoxyl 1,2-dihydro[1]benzothieno[3,2-b]pyrrol-3-one (9) takes place at temperatures above $550{ }^{\circ} \mathrm{C}$, but is accompanied by considerable decomposition leading to low yields. Both keto and enol tautomers, $\mathbf{9 K}$ and $\mathbf{9 E}$, exist in equilibrium in DMSO solution.

\section{Experimental Section}

General. ${ }^{1} \mathrm{H}$ and ${ }^{13} \mathrm{C}$ NMR spectra were recorded at 200 (or 250) and 50 (or or 63) MHz, respectively, for solutions in $\left[{ }^{2} \mathrm{H}\right]$ chloroform unless otherwise stated. Coupling constants are quoted in $\mathrm{Hz}$. ${ }^{13} \mathrm{C} \mathrm{NMR}$ parameters refer to one $\mathrm{CH}$ signal unless otherwise stated. Mass spectra were recorded under electron impact conditions.

\section{2-Acetyl-3-azido[1]benzothiophene (11)}

2-Acetyl-3-aminobenzo[b]thiophene $(\mathbf{1 0})^{5}$ (570 $\mathrm{mg}, 2.98 \mathrm{mmol}$ ) was dissolved in hot conc. phosphoric acid (10 $\mathrm{cm}^{3}$ ) and cooled to $0{ }^{\circ} \mathrm{C}$. A solution of sodium nitrite $(296 \mathrm{mg}, 4.29 \mathrm{mmol})$ in the minimum amount of water was added dropwise, and the mixture was stirred for $30 \mathrm{~min}$ keeping the temperature at $0{ }^{\circ} \mathrm{C}$. A solution of sodium azide ( $365 \mathrm{mg}, 5.62 \mathrm{mmol}$ ) in the minimum amount of water was added dropwise, and the solution stirred for a further $30 \mathrm{~min}$. The resulting precipitate was filtered and washed with water to yield 2-acetyl-3azidobenzo[b]thiophene (11) (306 mg, 47\%); $\mathrm{mp} \mathrm{60-62}{ }^{\circ} \mathrm{C}$ (from ethanol). (Found: $\mathrm{M}^{+}, 217.0310, \mathrm{C}_{10} \mathrm{H}_{7} \mathrm{~N}_{3} \mathrm{OS}$ requires $M$ 217.0310); $\delta_{\mathrm{H}} 2.67(3 \mathrm{H}, \mathrm{s}$, acetyl), $7.49(1 \mathrm{H}, \mathrm{m}, \mathrm{Ar}-\mathrm{H}), 7.53(1 \mathrm{H}, \mathrm{m}, \mathrm{Ar}-\mathrm{H}), 7.79(1 \mathrm{H}, \mathrm{m}, \mathrm{Ar}-\mathrm{H})$ and $8.00(1 \mathrm{H}, \mathrm{m}, \mathrm{Ar}-\mathrm{H}) ; \delta_{\mathrm{C}} 29.7\left(\mathrm{CH}_{3}\right), 123.1,123.1,125.1,127.3$ (quat), 128.4, 134.2 (quat), 134.3 (quat), 138.5 (quat) and 191.3 (quat); $\mathrm{m} / \mathrm{z} 217\left(\mathrm{M}^{+}, 6 \%\right), 189$ (92), 161 (100), 146 (55), 103 (46) and 59 (38). The crystallographic data has been deposited at the Cambridge Crystallographic Data Centre and assigned the code number CCDC 1408196.

\section{Flash vacuum pyrolysis reactions}

The precursor was volatilized under vacuum through an empty, electrically heated silica tube $(35 \times 2.5 \mathrm{~cm})$ and the products were collected in a U-tube cooled with liquid nitrogen, situated at the exit point of the furnace. CAUTION: aryl azides are potentially explosive when heated. Although we experienced no problems with the reactions reported here, the following precautions were always taken: 1 . Each individual pyrolysis was carried out on a scale no greater than $250 \mathrm{mg}$., 2. A metal inlet heater was always used, and 3. The apparatus was protected by a blast shield while in use. Upon completion of the pyrolysis, the trap was allowed to warm to room temperature under a nitrogen atmosphere. The entire pyrolysate was dissolved in solvent and removed from the trap. The precursor, pyrolysis conditions [quantity of precursor, furnace temperature $\left(T_{f}\right)$, inlet temperature $\left(T_{i}\right)$, pressure $(P)$ and pyrolysis time $\left.(t)\right]$ and products are quoted.

\section{FVP of 2-acetyl-3-azido[1]benzothiophene (11)}

FVP of 2-acetyl-3-azido[1]benzothiophene (11) $\left(60 \mathrm{mg}, 0.27 \mathrm{mmol}, \mathrm{T}_{\mathrm{f}} 300{ }^{\circ} \mathrm{C}, \mathrm{T}_{\mathrm{i}} 6{ }^{\circ} \mathrm{C}, \mathrm{P} 2.8 \times 10^{-2} \mathrm{Torr}, \mathrm{t} 10\right.$ $\mathrm{min}$ ) yielded 3-methyl[1] benzothieno[3,2-c]isoxazole (12) (38 mg, 72\%); (Found: $\mathrm{M}^{+}, 189.0246 . \mathrm{C}_{10} \mathrm{H}_{7} \mathrm{NOS}$ 
requires $M$ 189.0248); $\delta_{\mathrm{H}} 2.62(3 \mathrm{H}, \mathrm{s}$, acetyl), $7.41(1 \mathrm{H}, \mathrm{m}, \mathrm{Ar}-\mathrm{H}), 7.49(1 \mathrm{H}, \mathrm{m}, \mathrm{Ar}-\mathrm{H}), 7.64(1 \mathrm{H}, \mathrm{m}, \mathrm{Ar}-\mathrm{H})$ and $8.09(1 \mathrm{H}, \mathrm{m}, \mathrm{Ar}-\mathrm{H}) ; \delta_{\mathrm{C}} 12.0\left(\mathrm{CH}_{3}\right), 113.9$ (quat), 124.00, 124.1, 124.16 (quat), 125.2, 129.7, 147.6 (quat), 159.5 (quat) and 166.6 (quat); $\mathrm{m} / \mathrm{z} 189\left(\mathrm{M}^{+}, 100 \%\right), 161$ (95), 146 (78), 130 (29), 103 (61) and $76(25)$.

The pyrolysate of the FVP of 2-acetyl-3-azido[1] benzothiophene (11) (100 mg, $0.47 \mathrm{mmol}, \mathrm{T}_{f} 600{ }^{\circ} \mathrm{C}, \mathrm{T}_{\mathrm{i}} 60^{\circ} \mathrm{C}, \mathrm{P}$ $2.6 \times 10^{-2}$ Torr, t $12 \mathrm{~min}$ ) was washed through first with chloroform then acetone to and the solvent evaporated to yield a residue of pure 1,2-dihydro[1]benzothieno[3,2-b]pyrrol-3-one (9) (ca. $10 \mathrm{mg}, 11 \%$ ). (Found: $\mathrm{M}^{+}$, 189.0244. $\mathrm{C}_{10} \mathrm{H}_{7} \mathrm{NOS}$ requires $M$ 189.0248); ${ }^{1} \mathrm{H}$ NMR spectroscopy in $\left[{ }^{2} \mathrm{H}_{6}\right.$ ]DMSO equilibrated at $80 \%$ enol and $20 \%$ keto tautomer. $\delta_{\mathrm{H}}\left(\left[^{2} \mathrm{H}_{6}\right]\right.$-DMSO, $360 \mathrm{MHz}$, enol tautomer 9E); $6.62[1 \mathrm{H}, \mathrm{s}, \mathrm{H}(2)], 7.18[1 \mathrm{H}, \mathrm{m}$, $\mathrm{H}(6)], 7.34[1 \mathrm{H}, \mathrm{m}, \mathrm{H}(7)], 7.79[1 \mathrm{H}, \mathrm{m}, \mathrm{H}(8)]$ and $7.81[1 \mathrm{H}, \mathrm{m}, \mathrm{H}(5)] ; \delta_{\mathrm{H}}\left(\left[^{2} \mathrm{H}_{6}\right] \mathrm{DMSO}, 360 \mathrm{MHz}\right.$, keto tautomer 9K); $4.32\left(2 \mathrm{H}, \mathrm{s}, \mathrm{CH}_{2}\right), 7.51[1 \mathrm{H}, \mathrm{m}, \mathrm{H}(7)], 7.60[1 \mathrm{H}, \mathrm{m}, \mathrm{H}(6)], 7.98[1 \mathrm{H}, \mathrm{m}, \mathrm{H}(5)], 8.05[1 \mathrm{H}, \mathrm{m}, \mathrm{H}(8)]$ and $8.32[1 \mathrm{H}$, br s, NH]; $\delta_{\mathrm{C}}\left(\left[{ }^{2} \mathrm{H}_{6}\right]-\mathrm{DMSO}, 90 \mathrm{MHz}\right.$, enol tautomer 9E) 107.0 [C(2)], 109.9 [quat, C(3a)], 118.5 [C(8)], 122.4 $[C(6)], 124.1[C(7)], 124.2$ [C(5)], 127.8 [quat, $C(8 a)$ ], 129.9 [quat, $C(8 b)$ ], 137.1 [quat, $C(3)$ ], and 140.7 [quat, $\mathrm{C}(4 \mathrm{a})] ; \delta_{\mathrm{C}}\left(\left[{ }^{2} \mathrm{H}_{6}\right]\right.$-DMSO, $90 \mathrm{MHz}$, keto tautomer 9K) $60.1\left[\mathrm{CH}_{2}, \mathrm{C}(2)\right], 109.5$ [quat, $\left.\mathrm{C}(3 \mathrm{a})\right], 123.6$ [C(8)], 125.0 [C(7)], $125.2[C(5)], 126.0$ [quat, $C(8 a)$ ], 129.5 [C(5)], 148.0 [quat, $C(4 a)$ ], 171.4 [quat, $C(8 b)$ ] and 190.4 [quat, $\mathrm{C}(3)] ; m / z 189\left(\mathrm{M}^{+}, 100 \%\right), 188(82), 176(91), 161(48), 105$ (78) and $77(49)$.

\section{Temperature Profile of FVP of 2-acetyl-3-azido[1]benzothiophene (11)}

The pyrolyses were carried out (typically $31 \mathrm{mg}, 0.14 \mathrm{mmol}, \mathrm{T}_{\mathrm{i}} 60{ }^{\circ} \mathrm{C}, \mathrm{P} 1.9 \times 10^{-2}$ Torr, $\mathrm{t} 6 \mathrm{~min}$ ) at the temperatures described in the following table, with the following peaks in the ${ }^{1} \mathrm{H} N M R$ spectrum of the product mixture used to calculate the product ratio: 2-acetyl-3-azido[1]benzothiophene thiophene (11) [2.67 $(3 \mathrm{H}, \mathrm{s}$, acetyl), $7.79(1 \mathrm{H}, \mathrm{m}, \mathrm{Ar}-\mathrm{H})$ and $8.00(1 \mathrm{H}, \mathrm{m}, \mathrm{Ar}-\mathrm{H})]$ and 3-methyl[1]benzo]thieno[3,2-c]isoxazole (12) [2.62 (3H, s, acetyl), $7.64(1 \mathrm{H}, \mathrm{m}, \mathrm{Ar}-\mathrm{H})$ and $8.09(1 \mathrm{H}, \mathrm{m}, \mathrm{Ar}-\mathrm{H})$ ]; 1,2-dihydro[1]benzothieno[3,2-b]pyrrol-3-one (9) as its enol tautomer $[6.62(1 \mathrm{H}, \mathrm{s}, \mathrm{H}(2)]$. At higher temperatures unidentified thermal decomposition products appeared in the product mixture (see Discussion section).

Table 2. Data for the temperature profile of 11 , forming 12 and 9

\begin{tabular}{cccccc}
\hline $\begin{array}{c}\text { Temperature } \\
/{ }^{\circ} \mathrm{C}\end{array}$ & 200 & 300 & 400 & 500 & 600 \\
\hline $\mathbf{1 1} \%$ & 81 & 0 & 0 & 0 & 0 \\
$\mathbf{1 2} \%$ & 19 & 100 & 86 & 10 & 0 \\
$\mathbf{9} \%$ & 0 & 0 & 14 & 90 & 100 \\
\hline
\end{tabular}

\section{Crystallography data}

Diffraction data for $\mathbf{1 0}$ and $\mathbf{1 1}$ were collected with Mo-K $\alpha$ radiation on a Bruker Smart Apex diffractometer equipped with an Oxford cryosystems low-temperature device operating at $150 \mathrm{~K}$.

Crystal data for 10. $\mathrm{C}_{10} \mathrm{H}_{9} \mathrm{NOS}, M=191.25$. Orthorhomic, space group $P 2{ }_{1} 2_{1} 2_{1} . a=10.1472(8), b=12.5954(10)$, $c=14.3300(12) \AA, V=1831.5(3) \AA^{3}, Z=8$. The structure was solved by Patterson methods (DIRDIF) ${ }^{11}$ and refined by full matrix least squares against $F^{2}$ (Crystals). ${ }^{12}$ All non-H atoms were refined with anisotropic displacement parameters and $\mathrm{H}$-atoms were placed in calculated positions. The final $R$ factor, based on $F$ and 4416 out of 4495 data with $F>4 \sigma(F)$, was 0.0351 . The final difference map extremes were $\pm 0.50 \mathrm{e} \AA^{-3}$.

Crystal data for 11. $\mathrm{C}_{10} \mathrm{H}_{7} \mathrm{~N}_{3} \mathrm{OS}, M=217.25$. Monoclinic, space group $P-1 . a=7.7220(3), b=9.7725(4), c=$ 13.7905(6) $\AA, \alpha=76.880(20)^{\circ}, \beta=77.566(2)^{\circ}, \gamma=74.225(2)^{\circ}, V=962.15(7) \AA^{3}, T=150 \mathrm{~K}, Z=4$. The structure 
was solved by direct methods (Shelxs) ${ }^{13}$ and refined by full matrix least squares against $F^{2}$ (Crystals). All non-H atoms were refined with anisotropic displacement parameters and H-atoms were placed in calculated positions. The final $R$ factor, based on $F$ and 1913 out of 4427 data with $F>4 \sigma(F)$, was 0.0399 . The final difference map extremes were -0.27 and $+0.38 \mathrm{e}^{-3}$.

\section{Acknowledgements}

We are grateful to The EPSRC for a research studentship (to A. P. G.) and for the award of a diffractometer, and to Professor S. Parsons and Dr. P. A. Wood for the X-ray crystal structures.

\section{Supplementary Material}

Experimental procedure for compound 10, NMR analyses, and X-ray tables are available in the Supplementary Material file available on the publisher's website.

\section{References}

1. Gaywood, A. P.; McNab, H. Synthesis, 2010, 1361-1364.

https://doi.org/10.1055/s-0029-1218668

2. Gaywood, A. P.; McNab, H. J. Org. Chem., 2009, 74, 4278-4282.

https://doi.org/10.1021/jo900496u

3. Gaywood, A. P.; McNab, H. Org. Biomol. Chem., 2010, 8, 5166-5173

https://doi.org/10.1039/c0ob00076k

4. Wentrup, C.; Tetrahedron, 1971, 27, 367-374)

https://doi.org/10.1016/S0040-4020(01)90706-9

5. Carrington, D. E. M.; Clarke, K.; Scowston, R. M. J. Chem. Soc. (C), 1971, 3903-3906.

https://doi.org/10.1039/j39710003903

6. Barechi, F.; Coiro, V. M. Acta Crystallogr., Sect. C: Cryst. Struct. Commun., 1988, 44, 1449-1451. https://doi.org/10.1107/S0108270188002793

7. Benassi, R.; Folli, U.; Iarossi, D.; Musatti, A.; Nardelli, M.; Schenetti, L.; Taddei, F. J. Chem. Soc., Perkin

Trans. 2, 1987, 1851-1859.

https://doi.org/10.1039/p29870001851

8. Tchertanov, L. Acta Crystallogr., Sect. B, 1999, 55, 807-809.

https://doi.org/10.1107/S0108768199003936

9. Degl'Innocenti, A.; Funicello, M.; Scafato, P.; Spagnolo, P. J. Chem. Soc., Perkin Trans. 1, 1995, 2141-2145. https://doi.org/10.1039/p19950002141

10. Domene, C.; Jenneskens, L. W.; Fowler, P. W. Tetrahedron Lett., 2005, 46, 4077-4080. https://doi.org/10.1016/j.tetlet.2005.04.014

11. Beurskens, P. T.; Beurskens, G.; Bosman, W. P.; de Gelder, R.; Garcia Granda, S.; Gould, R. O.; Israel, R.; Smits, J. J. M. (1996) a Computer Program System for Crystallography Laboratory, University of Nijmegen, Toernooiveld 1, 6525 ED Nijmegen, The Netherlands. 
12. Betteridge, P. W.; Carruthers, J. R.; Cooper, R. I.; Prout, K.; Watkin, D. J. J. Appl. Cryst., 2003, 36, 1487. https://doi.org/10.1107/S0021889803021800

13. Sheldrick, G. M. (1986). SHELXS86. Program for the solution of crystal structures. Univ. of Göttingen, Federal Republic of Germany.

This paper is an open access article distributed under the terms of the Creative Commons Attribution (CC BY) license (http://creativecommons.org/licenses/by/4.0/) 